\title{
ENVOLVIMENTO SUSTENTÁVEL: $O$ UFPE NA PRAÇA INCENTIVANDO A EDUCAÇÃO AMBIENTAL
}

\author{
Jéssika Kellyane da Silva Leite ${ }^{1}$ \\ Silvana Gonçalves Brito de Arruda ${ }^{2}$ \\ Leonio José Alves da Silva ${ }^{3}$ \\ Luís André de Almeida Campos ${ }^{4}$
}

Resumo: O presente artigo ressalta que o homem, atualmente, consome os produtos industrializados excessivamente, resultando na alta geração de resíduos sólidos, e a gestão inadequada, juntamente com excessiva produção, provoca inúmeras doenças, problemas sanitários relacionados à poluição dos mananciais, o assoreamento dos rios e córregos, entupimento de bueiros, contaminação do ar, entre outros. Nesse contexto, a Educação Ambiental deve ser incorporada ao processo de formação dos cidadãos, contribuindo para que se tornem sujeitos mais responsáveis e comprometidos com a sustentabilidade. O Programa UFPE Na Praça compromete-se com a promoção da Saúde e Educação Ambiental, seja em âmbitos de educação formais e/ou não formais.

Palavras-chave: A prática dos 3 R's; Educação Ambiental; Resíduos Sólidos.

\footnotetext{
${ }^{1}$ Universidade Federal de Pernambuco. Mestranda em Desenvolvimento e Meio Ambiente - PRODEMA. E-mail: jkellyane@yahoo.com

${ }^{2}$ Universidade Federal de Pernambuco. Centro Acadêmico de Vitória. Dra e Professora Adjunto IIE-mail: silgbrito@hotmail.com

${ }^{3}$ Universidade Federal de Pernambuco. Centro de Ciências Jurídicas. Pós-Doutor e Professor Adjunto de Direito Civil. E-mail: leonioalves@bol.com.br

${ }^{4}$ Universidade Federal de Pernambuco. Graduando em Licenciatura em Ciências Biológicas, Email: laacampos@hotmail.com
} 


\section{Introdução}

O quadro socioambiental que caracteriza as sociedades contemporâneas revela que os impactos dos humanos sobre o Meio Ambiente estão se tornando cada vez mais complexos, tanto em termos quantitativos quanto qualitativos. A reflexão sobre as práticas sociais, em um contexto marcado pela degradação permanente do Meio Ambiente e do seu ecossistema, envolve um necessário avanço com a produção de sentidos sobre a Educação Ambiental.

E a Política Nacional do Meio Ambiente, segundo a Lei de № 6.938, de 31 de Agosto de 1981 conforme descrito no Art. 2 tem por objetivo a preservação, melhoria e recuperação da qualidade ambiental propícia à vida, visando assegurar, no País, condições ao desenvolvimento socioeconômico, aos interesses da segurança nacional e à proteção da dignidade da vida humana, atendidos 10 princípios, descritos na Constituição, dentre os quais, destaca-se para interesse do referido artigo, o princípio $X$ - educação ambiental a todos os níveis de ensino, inclusive a educação da comunidade, objetivando capacitá-la para participação ativa na defesa do meio ambiente.

A partir da Conferência Intergovernamental sobre Educação Ambiental realizada em Tbilisi (URSS), em 1977, inicia-se um amplo processo em nível global orientado para criar as condições que formem uma nova consciência sobre o valor da natureza e para reorientar a produção de conhecimento baseada nos métodos da interdisciplinaridade $e$ nos princípios da complexidade. Na conferência estabeleceu-se também que o processo educativo deveria ser orientado para a resolução dos problemas concretos do Meio Ambiente, através de enfoques interdisciplinares e, de participação ativa e responsável de cada indivíduo e da coletividade, visando à expansiva dimensão ambiental e os atores envolvidos.

Conforme Jacobi (1999), a dimensão ambiental configura-se crescentemente como uma questão que envolve um conjunto de atores do universo educativo, potencializando o engajamento dos diversos sistemas de conhecimento, a capacitação de profissionais e a comunidade universitária numa perspectiva interdisciplinar. Nesse sentido, a produção de conhecimento deve necessariamente contemplar as inter-relações do meio natural com 0 social, incluindo a análise dos determinantes do processo, o papel dos diversos atores numa perspectiva que priorize novo perfil de desenvolvimento, com ênfase na sustentabilidade socioambiental.

Atualmente, o homem esta consumindo os produtos industrializados excessivamente, resultando numa alta geração de resíduos sólidos. Há apenas algumas décadas nós, humanos, despertamos para os problemas ambientais. Devido à constatação de que os resíduos eram uma fonte de degradação do Meio Ambiente, no final da década de 1960, passou-se a considerar, a problemática do lixo como uma questão ambiental (EIGENHEER, 2009). Esse despertar da nossa consciência fez-nos perceber que a questão do lixo é uma das mais preocupantes problemáticas que acomete ao planeta. 
Segundo ressalta Lemos (1999 p.64-72),

abordar este problema da produção a e destinação do lixo no processo de educação é um desafio, visto que a solução é encontrada quando o individuo compreende que ele é parte atuante do meio

O elevado consumismo e consequentemente a alta produção de resíduos, tem ocasionado um gerenciamento inadequado da destinação final desses resíduos, e, uma gestão inadequada dos resíduos, juntamente com sua excessiva produção, provoca inúmeras doenças, problemas sanitários relacionados à poluição dos mananciais, o assoreamento dos rios e córregos, entupimento de bueiros, contaminação do ar, entre outros. Além disso, a gestão dos resíduos tem se tornado um grande problema devido à falta de conscientização da população e de informação acerca de seu gerenciamento. Neste aspecto, a Educação Ambiental torna-se fundamental para um melhor manejo desses resíduos e com isso, a dos danos ambientais (GUSMÃO, 2000).

No contexto sobre os resíduos sólidos, a Lei de n 12.305/10, que institui a Política Nacional de Resíduos Sólidos (PNRS) é bastante atual e contém instrumentos importantes para permitir o avanço necessário ao País no enfrentamento dos principais problemas ambientais, sociais e econômicos decorrentes do manejo inadequado dos resíduos sólidos. Prevê a prevenção e a redução na geração de resíduos, tendo como proposta a prática de hábitos de consumo sustentável e um conjunto de instrumentos para propiciar o aumento da reciclagem e da reutilização dos resíduos sólidos (aquilo que tem valor econômico e pode ser reciclado ou reaproveitado) e a destinação ambientalmente adequada dos rejeitos (aquilo que não pode ser reciclado ou reutilizado).

A relação do homem com o ambiente natural torna-se, portanto, uma preocupação pertinente ao quadro ambiental e social na atualidade, por isso pensando na melhoria da qualidade de vida e na busca por alternativas menos agressivas, muitos segmentos da sociedade têm concentrado esforços no sentido de redirecionar práticas e formas de relação entre a população humana e o seu meio. Destacam-se a necessidade de redução do consumo e as ações vinculadas à reutilização e reciclagem de materiais. Comportamentos que convencionalmente descrevemos como os 3R's (redução, reutilização e reciclagem).

Em relação à conscientização e sensibilização quanto aos problemas são ainda maiores, pois, como diz Velloso (2004, p.02), "A educação ambiental está mais direcionada para a mudança de hábitos da população sobre a técnica da disposição domiciliar do lixo - coleta convencional e coleta seletiva do que com o consumismo gerado pelo processo de produção industrial da sociedade capitalista". Ao instigar a população a acolher a ideia de separação 
do lixo, não se pode excluir a conscientização em relação ao consumo e desperdício exagerados, provocados pela grande demanda de necessidades do homem e aos trabalhadores que são responsáveis pela destinação correta do lixo.

Nesse contexto, a Educação Ambiental deve ser incorporada ao processo de formação dos cidadãos, contribuindo para que os mesmos se tornem sujeitos mais responsáveis e comprometidos com a sustentabilidade e o futuro do planeta. Nessa direção, a problemática ambiental constitui um tema muito propício para aprofundar a reflexão e a prática em torno do restrito impacto das práticas de resistência e de expressão das demandas da população das áreas mais afetadas pelos constantes e crescentes agravos ambientais.

De modo que, os movimentos, grupos ou programas de extensão universitária, sensibilizados com a atual situação do planeta e sua crescente problemática ambiental, têm assumido para si essa responsabilidade social, a de propagar e multiplicar informações que favoreçam a população e que tragam benefícios também ao Meio Ambiente. Diante dessa perspectiva, $O$ programa UFPE NA PRAÇA, desenvolvido pelos departamentos de Saúde do Centro Acadêmico da Vitória (CAV), da Universidade Federal de Pernambuco (UFPE) tem buscado através de ações promotoras sobre Saúde e Educação, promover a saúde e Educação Ambiental nos mais diversos bairros, praças e comunidade da Vitória de Santo Antão - PE, ações sociais que refletem no bem estar das pessoas, e considerando a importância dessa temática, 0 Programa UFPE na Praça vem desenvolvendo atividades na área da educação ambiental e promovendo a sensibilização das pessoas em torno à problemática ambiental, bem como a importância de práticas saudáveis em melhoria da qualidade de vida.

Reconhecendo a importância de realizar ações pontuais sobre Educação Ambiental e toda a problemática em torno do Meio Ambiente, nos diversos bairros e comunidades participantes e ativas no Programa UFPE Na Praça, o referido estudo teve como objetivo analisar as informações que o grupo do estudo tinha acerca do Meio Ambiente e a demanda crescente dos problemas que as ações do homem têm refletido no ambiente e provocado e contribuído nos crescentes problemas ambientais.

A pesquisa teve o intuito de apontar ações sociais que promovessem a importância de práticas sustentáveis, e de como essas práticas podem e devem contribuir na mudança de hábitos dessas pessoas, bem como isso é refletido positivamente para o ambiente e gerações futuras. Outro argumento que justifica a referida pesquisa é a carência de ações desse nível, que criem também novas oportunidades de negócios que contribuíssem para a melhoria da qualidade de vida da população local e a sustentabilidade da região. 


\section{Procedimentos metodológicos}

O presente estudo tem como recorte espacial o bairro da Bela Vista, no município da Vitória de Santo Antão, Zona da Mata do Estado do Pernambuco. Sendo as ações da pesquisa realizadas com um grupo de senhoras da terceira idade, grupo e bairro ativo no Programa UFPE $\mathrm{Na}$ Praça, escolhidos aleatoriamente.

Para a realização da presente pesquisa utilizou-se como base metodológica o estudo teórico e empírico com uma abordagem de caráter descritivo - exploratório. Segundo Gil (2008, p. 42), a pesquisa descritiva tem como objetivo primordial a descrição das características de determinada população ou fenômeno. O mesmo autor afirma que a pesquisa exploratória tem como principal finalidade desenvolver, esclarecer e modificar conceitos e ideias, com vistas à formulação de problemas mais precisos, partindo do princípio que as análises a serem construídas representariam um cenário em construção para a comunidade, para os graduandos e para a instituição.

Inicialmente foi realizado um levantamento bibliográfico e documental sobre os assuntos voltados a Educação Ambiental, o crescimento desordenado dos centros urbanos e a alta produção de resíduos sólidos, sobre a Política Nacional de Resíduos Sólidos (PNRS), práticas e ações sustentáveis, dentre elas, destacou-se as ações e oficinas voltadas a política dos 3 R's. Foram consultados artigos, livros, teses, entre outros no intuito de conhecer os objetivos e o funcionamento das políticas públicas ambientais, e como outros lugares se comportam diante da problemática ambiental.

No segundo momento, realizou-se o levantamento empírico com visitas de campo no período da primeira semana de julho de 2013. Nesta etapa foram utilizadas técnicas de observação e realização de entrevistas estruturadas com as senhoras do grupo, buscando evidenciar a principal demanda do grupo, conhecer as principais necessidades daquela comunidade, bem como conhecer o nível de informações que o grupo possuía sobre a temática ambiental. Durante essa etapa e ações então desenvolvidas, objetivou-se trabalhar com a reutilização do papelão, um dos resíduos produzidos em grande quantidade na atualidade, e sendo realidade marcante naquela comunidade, buscando evidenciar a importância e benefícios desse ato para 0 Meio Ambiente e para a saúde humana.

Posteriormente a essas ações, e analisados os primeiros dados obtidos com a aplicação dos questionários, foram estabelecidos os dias e as ações consecutivas a serem desenvolvidas, sendo determinados os encontros do mês de agosto, que geralmente ocorrem uma vez por semana, para que fossem desenvolvidas as oficinas de reutilização do papelão. Os planos de desenvolvimento das oficinas são detalhados na (Tabela 1). 
Tabela 1: A tabela ilustra o esquema proposto para a realização das atividades práticas durante o mês de agosto.

\begin{tabular}{|c|c|c|c|}
\hline OFICINA & TíTULO & FINALIDADE & $\begin{array}{l}\text { DIA DA } \\
\text { OFICINA }\end{array}$ \\
\hline 01 & $\begin{array}{l}\text { "Lixo X As novas } \\
\text { possibilidades" }\end{array}$ & $\begin{array}{l}\text { Uma abordagem teórica, mencionados os } \\
\text { tipos de resíduos segundo a Política } \\
\text { Nacional de Resíduos Sólidos, abordando } \\
\text { a linha dos resíduos não biodegradáveis e } \\
\text { biodegradáveis, buscando evidenciar o } \\
\text { tempo de degradação do papelão no Meio } \\
\text { Ambiente, sua utilização e as novas } \\
\text { possibilidades de baixo custo para a sua } \\
\text { reutilização. }\end{array}$ & 06/08/ \\
\hline 02 & $\begin{array}{l}\text { "Rolinhos de papel } \\
\text { no lixo? Não mais" }\end{array}$ & $\begin{array}{l}\text { As atividades da oficina objetivam } \\
\text { promover um novo uso para os rolos de } \\
\text { papel higiênicos, transformando-os em } \\
\text { flores para decoração, buscando } \\
\text { incentivar o uso de utensílios disponíveis } \\
\text { em casa, para a confecção e decoração } \\
\text { da flor decorativa. }\end{array}$ & $13 / 08 /$ \\
\hline 03 & $\begin{array}{c}\text { "Criando as suas } \\
\text { embalagens de } \\
\text { presentes" }\end{array}$ & $\begin{array}{l}\text { O objetivo dessa ação foi reutilizar rolos } \\
\text { de papel para confeccionar as } \\
\text { embalagens de presentes e porta-objeto. } \\
\text { Incentivando o uso de diversos itens para } \\
\text { o acabamento do produto final. }\end{array}$ & 20/08/ \\
\hline 04 & $\begin{array}{c}\text { "Criando um novo } \\
\text { espaço para } \\
\text { livros/revistas" }\end{array}$ & $\begin{array}{l}\text { A oficina promoveu a confecção de porta- } \\
\text { livro/revistas, reutilizando a caixa de } \\
\text { cereal ou caixas de leite, incentivando a } \\
\text { reutilização de retalhos de tecidos para o } \\
\text { acabamento do novo produto. }\end{array}$ & $27 / 08 /$ \\
\hline
\end{tabular}

Fonte: De autoria do Programa UFPE na Praça.

Posteriormente as oficinas, o mesmo questionário foi aplicado, buscando analisar a visão daquele grupo depois de toda abordagem teóricoprática.

A análise dos resultados ocorreu com uma abordagem qualitativa, considerando esta mais pertinente para entender as abordagens que as práticas em Educação Ambiental possibilitam seus processos e interações sociais. Segundo Richardson (1999, p. 39) a analise qualitativa pode "descrever a complexidade de determinado problema, analisar a interação de certas variáveis, compreender e classificar processos dinâmicos vividos por grupos sociais".

Os dados coletados possibilitaram compreender como aquele grupo do estudo, vem lidando com a problemática ambiental, bem como isso vem sendo abordado na região, ressaltar a importância do envolvimento da comunidade local no processo de promoção da Educação Ambiental e apontar possibilidades de desenvolvimento da comunidade que contribua para a sustentabilidade do planeta e a melhoria da qualidade de vida. 


\section{Resultados e Discussão}

As ações do Projeto UFPE $\mathrm{Na}$ Praça buscaram por meio das abordagens realizadas com os sujeitos envolvidos, sensibilizá-los quanto a mudanças de hábitos em relação a práticas sustentáveis, e o quanto essas ações são positivas para o Meio Ambiente, envolvendo aquela comunidade da construção de uma conscientização também sobre a importância e a preservação do Meio Ambiente.

Sendo a problemática ambiental um tema complexo, precisando ser muito estudado e que por consequência aborda diversas áreas, dentre elas econômicas, culturais, ecológicas, buscou-se nas oficinas uma abordagem interdisciplinar, tendo base em Edgar Morin, que é autor dos mais contundentes em relação a interdisciplinaridade do saber "Os conhecimentos fragmentados só servem para usos técnicos. Não conseguem conjugar-se para alimentar um pensamento capaz de considerar a condição humana no âmago da vida, na terra, no mundo, e de enfrentar os grandes desafios de nosso época" (MORIN, 2000, p.39). Buscando desenvolver a teoria abordada na literatura, sem deixar de lado as informações e saberes daquele grupo e procurando desafiá-las em suas habilidades.

Ao final de cada oficina realizada com o grupo de senhoras da terceira idade um novo objeto era confeccionando, cada participante ao termino da ação tinha um novo objeto transformado, e apresentando um olhar sensibilizado diante de um simples rolo de papel, sendo com isso um dos objetivos alcançados pelo grupo, e tudo possuindo o papelão como base do processo de reutilização. E trazendo a abordagem para a contextualização dos 3 R's, reduzir, reutilizar e reciclar. Alguns autores apresentam essa prática como um fator impulsionador na vida de comunidades mais carentes, sem tão pouco deixar lado a interdisciplinaridade da questão.

De acordo com Calderoni (1996, p.9),

a reciclagem do lixo apresenta relevância ambiental, econômica e social, com implicações que se desdobram em esferas como as seguintes: organização espacial; preservação; conservação; geração de empregos; geração de renda...

Durante os contextos teóricos abordados no decorrer da palestra, a participação do grupo de senhoras da comunidade Bela Vista foi proveitosa, tendo em vista aquele momento não ser apenas de passagem de informações e teorias, mas da construção do conhecimento do grupo em torno da problemática ambiental, possuindo, portanto, um aspecto significativo para 0 desenrolar das ações da pesquisa (Figura 1). 


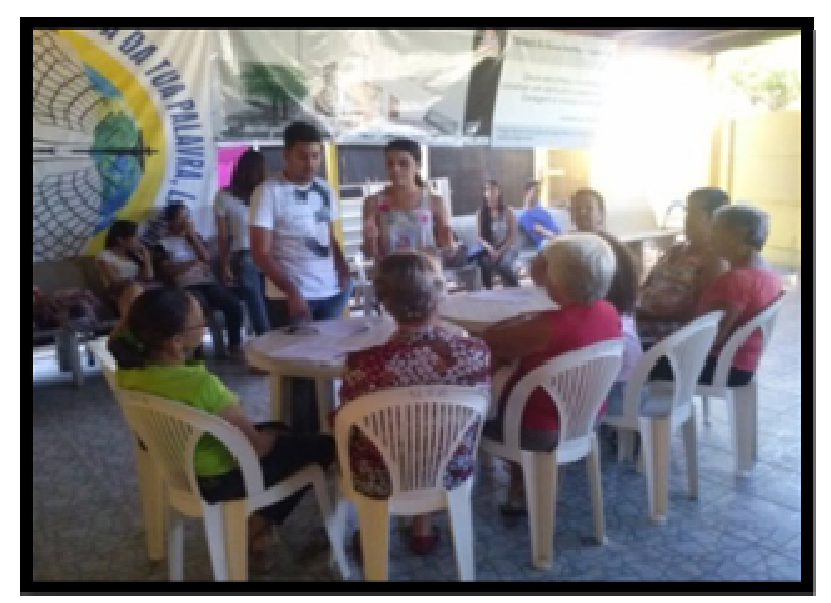

Figura 1: Teoria e prática sobre papelão durante a realização da oficina. Fonte: Acervo fotográfico do Programa UFPE na Praça (2014).

As oficinas trazem como característica, a abertura de espaços de aprendizado e uma relação de aproximação entre os sujeitos envolvidos, sejam os mediadores do processo, sejam para o público que participa das ações da oficina.

Com base em Vieira et al. (2002, p.17),

na oficina surge um novo tipo de comunicação entre professores e alunos. É formada uma equipe de trabalho, onde cada um contribui com sua experiência. O professor é dirigente, mas também aprendiz. Cabe a ele diagnosticar o que cada participante sabe e promover o ir além do imediato.

À vista disso, as oficinas buscam desenvolver um dialogo entre os participantes e aproximar a temática abordada com o contexto local das comunidades em geral, sempre focando o que cada um pode promover para a construção e o desenvolvimento das ações práticas das oficinas. As atividades de reutilização do papelão, juntamente com os rolos de papel higiênico, as caixas de cereal e de leite proporcionaram além da confecção e produção da flor (Figura 2), embalagem de presente (Figura 3) e o porta livros e revistas (Figura 4), respectivamente, proporcionou também aprendizados e a criação de novas possibilidades. 


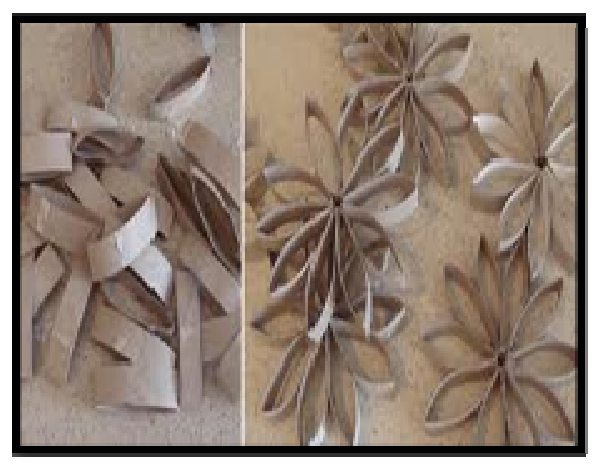

Figura 2: As flores confeccionadas durante as oficinas reutilizando o papelão. Fonte: Acervo fotográfico do Programa UFPE na Praça (2014).

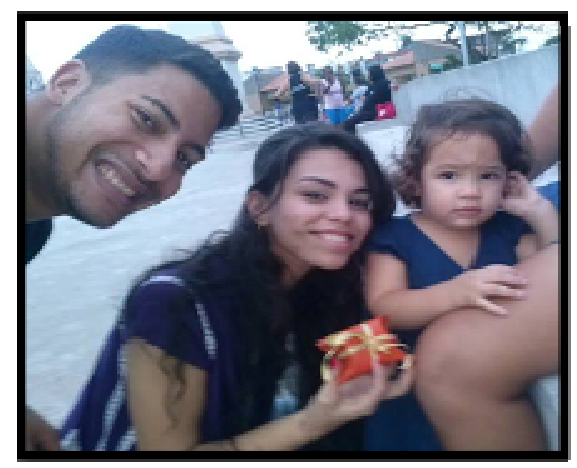

Figura 3: Confecção de embalagem de presente durante as oficinas reutilizando o papelão. Fonte: Acervo fotográfico do Programa UFPE na Praça (2014).

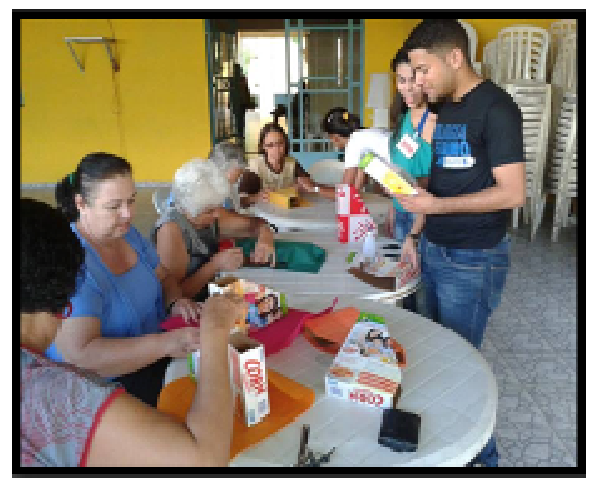

Figura 4: Confecção: porta-livro e revistas durante as oficinas reutilizando o papelão.

Fonte: Acervo fotográfico do Programa UFPE na Praça (2014).

No primeiro contato com o grupo de senhoras da comunidade foi realizado a aplicação de um questionário, que pode ser definido "como a técnica de investigação composta por um número mais ou menos elevado de questões apresentadas por escrito às pessoas, tendo por objetivo o Revbea, São Paulo, V. 10, N 1: 301-315, 2015. 
conhecimento de opiniões, crenças, sentimentos, interesses, expectativas, situações vivenciadas etc." (GIL 1999, p.128). Nesse sentido, a técnica da aplicação do questionário serviu para coletar as informações e necessidades da realidade daquela comunidade.

A primeira aplicação do questionário permitiu avaliar o nível do grupo de senhoras da Bela Vista quanto às questões sobre o Meio Ambiente, tanto quanto estão perceptíveis as problemáticas do tema, bem como a importância da prática de ações sustentáveis, e como isso pode contribuir para a melhoria de suas vidas e do ambiente ao redor. Com o primeiros dados analisados e com base nas oficinas planejadas, visou-se abordar como o papelão, um resíduo facilmente encontrado em suas casas, contribui com os problemas do Meio Ambiente e como a aplicação dos 3 R's pode minimizar esses impactos.

O questionário era composto por cinco questões, duas discursivas e três de múltipla escolha. Nas duas primeiras questões era pedido que escrevessem o que elas entendiam por resíduos sólidos urbanos e quais os problemas ambientais da comunidade. Em relação aos problemas ambientais da comunidade todas as respostas traziam a questão do lixo, as formas inadequadas que a população descartava e também sobre a falta de conscientização das pessoas. "As pessoas acham que o lixo deve ser jogado em toda esquina, porque é o que mais têm por aqui" relatou uma das senhoras em sua resposta.

Em relação aos resíduos sólidos muitas descreveram como sendo " $O$ lixo separado das comidas", ou "resíduos sólidos são 'aqueles lixo' que a gente joga, mais pode fazer algo deles", ou então "é o nome dado para o lixo quando ele é estudado". Essas respostam deixam claro que muitas vezes as pessoas conhecem um pouco do assunto, mesmo sem terem pesquisado mais profundo sobre o assunto, ou até mesmo como elas falaram "a gente vê essas coisas no jornal, serem faladas" e também "nos postinhos de saúde as moças às vezes falam do lixo, das doenças". Portanto, percebeu-se ser de suma importância a participação de projetos e ações mais efetivas sobre o Meio Ambiente, que não sejam direcionadas em espaços apenas formais, mas com enfoque também nos espaços não-formais de educação.

Conforme alguns autores afirmam, a educação, enquanto forma de ensino-aprendizagem, é adquirida ao longo da vida dos cidadãos e pode ser dividida em três diferentes formas: educação escolar formal desenvolvida nas escolas; educação informal, transmitida pelos pais, no convívio com amigos, em clubes, teatros, leituras e outros, e educação não-formal, que ocorre quando existe a intenção de determinados sujeitos em criar ou buscar determinados objetivos fora da instituição escolar.

No segundo momento da aplicação dos questionários, observou-se repostas mais elaboradas e bem formadas como: "os resíduos sólidos urbanos são o que chamamos de lixo e os descartamos de forma errada", ou "os resíduos sólidos são os lixos de nossas casas, empresas, escolas e todos os outros lugares". E em relação aos problemas da comunidade, as respostas 
continuaram parecidas, mas agora elas destacam as ações das políticas públicas como algo que, quando for efetivo, será de grande importância para a melhoria da qualidade de vida da comunidade, "o problema do nosso lixo é sim muitas vezes culpa nossas, pois não sabemos como descartar corretamente ou então misturamos tudo, mas vai ser diferente agora, e quando a prefeitura passar a trabalhar também com esses assuntos do meio ambiente, vai melhorar muito". O que deixa claro e torna positivo o resultado das ações que envolvam teoria e práticas, associados aos problemas de uma comunidade, facilitam na construção e desenvolvimento do conhecimento.

Já as questões de múltipla escolha visavam abordar sobre os problemas ambientais conhecidos pelo o grupo (Figura 5), para as analises posteriores sobre como as oficinas enriqueceriam as informações do grupo.
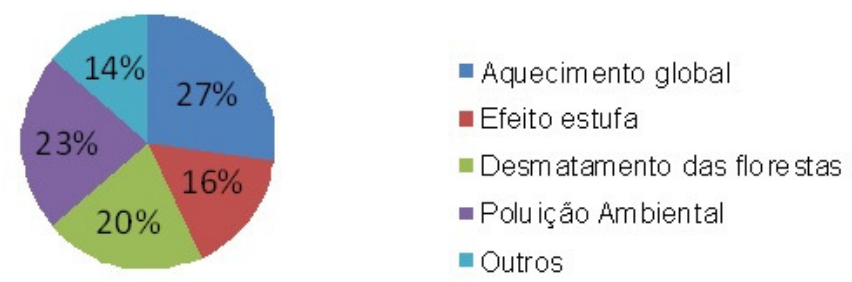

Figura 5: Representação do conhecimento sobre questões ambientais. Fonte: De autoria do Programa UFPE na Praça (2014).

De acordo com os dados da figura 5, foi permitido que durante as oficinas fosse dada ênfase em alguns dos assuntos pouco conhecido na realidade daquele grupo, tentando relacionar o que o descarte incorreto do papelão promovia nesses assuntos, buscando relacionar sempre com o objeto de estudo, o papelão. Quando o questionário foi aplicado novamente, o grupo acrescentou algumas respostas que não estavam descritas anteriormente, como os gases de efeito estufa, poluição dos rios, mares, entre outros.

Em relação às práticas ou a ausência de práticas sustentáveis, se elas desenvolviam esse hábito (Figura 6).

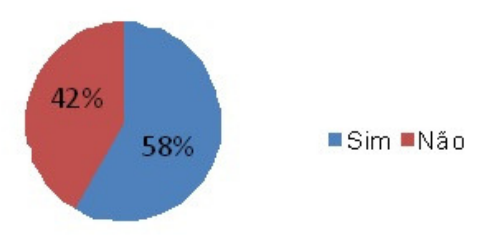

Figura 6: Representação da reflexão sobre os hábitos e práticas sustentáveis.

Fonte: De autoria do Programa UFPE na Praça (2014).

Em relação à Figura 6, na primeira aplicação obteve-se um resultado de $58 \%$ das senhoras que desenvolviam algum tipo de prática sustentável, sendo 
incentivadas as demais a participar desse grupo de pessoas que procuram desenvolver novos hábitos e práticas que venha a favorecer o Meio Ambiente, como a própria comunidade em questão. No segundo momento da aplicação do questionário, obteve-se o percentual de $100 \%$ das senhoras do grupo a adotarem e assumir uma postura enquanto sujeitos mais preocupados com 0 ambiente, assumindo uma postura de sujeito ecológico, aquele que é atuante e se preocupa como suas ações refletem para o Meio Ambiente.

Perante a esta circunstância, a construção de uma nova postura global, preocupada com o meio ambiente e as práticas sustentáveis traz a tona 0 debate acerca da formação de um sujeito ecológico (CARVALHO, 2008, p. 67), que vislumbra o ideário de ser e viver em um mundo ambientalmente sadio e ecológico, um novo estilo de vida, e principalmente um novo modo de pensar as relações com os outros e com mundo. O sujeito ecológico é, portanto, um conceito que caracteriza aspectos dos sujeitos que são orientados e conduzidos por valores e concepções ecológicas.

Segundo Carvalho (2008, p. 67),

o sujeito ecológico agrega uma série de traços, valores e crenças e poderia ser descrito em facetas variadas. Em sua versão política, poderia ser apresentado como sujeito heroico, vanguarda de um movimento histórico, [...] protagonista de novo paradigma político-existencial. Em sua versão Nova Era, é visto como alternativo, integral, equilibrado, harmônico, planetário, holista. Em sua versão gestor social, supõe-se que partilhe de uma compreensão política e técnica da crise socioambiental, sendo responsável por adotar procedimentos e instrumentos legais para enfrentá-la, por mediar os conflitos e planejar ações.

A última abordagem foi sobre que tipos de práticas sustentáveis auxiliam o Meio Ambiente e devem ser desenvolvidas por cada um (Figura 7).

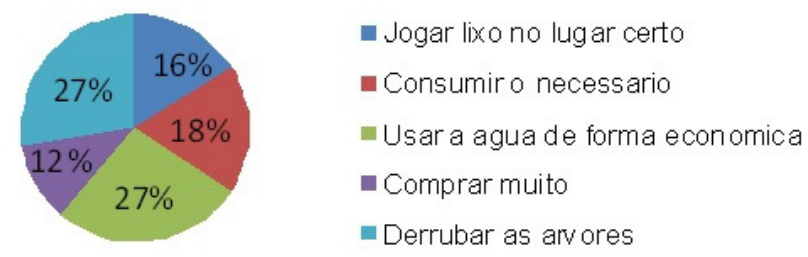

Figura 7: Práticas Sustentáveis que auxiliam o Meio Ambiente.

Fonte: De autoria do Programa UFPE na Praça (2014). 
para melhorar o Meio Ambiente, entretanto, o uso da madeira chama atenção, sendo falado por elas o uso da madeira na construção dos móveis de casa. Em um segundo momento, o grupo mostrou-se mais atento as práticas que são e promovam resultados positivos ao Meio Ambiente, dentre as citadas, o grupo acrescentou a prática efetiva da coleta seletiva, mais ações educadoras nos postos de saúde, como também os hábitos que a teoria dos 3 R's desenvolve.

A realização das oficinas, em conjunto com as análises dos questionários e os relatos do cotidiano do grupo de senhoras em questão, percebeu-se que os conteúdos abordados durante as ações estão influenciando diretamente na sua vida particular de cada uma, pois os diálogos desenvolvidos pelos atores da pesquisa possibilitaram perceber isso, e ainda notou-se que as atividades de confecções de materiais a partir dos resíduos sólidos passaram a ser um hobby, onde elas relaxam e divertem-se e procuram lucrar economicamente com os novos objetos confeccionados.

De forma significativamente ocorreu uma mudança de atitudes e a preocupação com as questões ambientais e com o Meio Ambiente aumentaram de forma que elas revelaram-se disseminadoras do conhecimento adquirido nos encontros ocorridos durante as atividades da pesquisa, visto que aconselham os filhos, os netos a cuidarem melhor do meio, um espaço de todos, a compreender como pode-se reutilizar materiais denominados de lixo e entender que atitudes ecologicamente corretas podem melhorar a questão da saúde humana e tornar o ambiente em que todos estão inseridos melhor de viver.

As respostas revelam que as ações no campo da Educação Ambiental devem ser intensificadas nos espaços não-formais da Educação, orientando a construção de conhecimento, novos valores e comportamentos comprometidos com a conservação e preservação ambiental.

Durante o desenvolvimento das oficinas foi possível observar que aquelas senhoras tiravam o máximo de aproveitamento daqueles momentos, como para tirar dúvidas e também acrescentar algo produtivo no decorrer das oficinas. Com a realização das atividades, o desenvolvimento de cada um e os relatos do cotidiano das senhoras, foi perceptível que os conteúdos abordados estão influenciando diretamente na sua vida, percebeu-se que as atividades de confecções de materiais a partir dos resíduos sólidos tornaram-se um hobby, onde elas relaxam e divertem-se.

\section{Conclusões}

A sensibilização das pessoas as questões ambientais tem como alicerce a Educação Ambiental, que assume a condição de principal meio para promover a mudança de pensamentos e atitudes, favorecendo o exercício da condição cidadã. As ações em Educação Ambiental têm como objetivo sensibilizar as pessoas em relação ao mundo em que vivem e o papel individual e coletivo na busca por melhores condições ambientais e um futuro sustentável.

revista brasileira educação ambiental 
Os dados levantados com essa pesquisa são relevantes à medida que podem ser utilizados como referência para orientar novas intervenções nos espaços escolares, ampliando a função social da escola nesse processo.

Pode-se considerar que a Educação Ambiental é uma forte ferramenta para melhorar a situação atual do planeta, e ela aliada a extensão promovida pelas Universidades torna-se forte arma social na mudança da realidade predominante nas comunidades com menos acesso a informação, no desenvolvimento do senso crítico dos moradores, na reflexão de como o modelo econômico está degradando o Meio Ambiente, como também na formação do cidadão com perspectivas melhores e mais sustentáveis para seu futuro, bem como o do planeta.

Nesse contexto, as reflexões acerca da efetivação de ações educativas em prol da reutilização de resíduos sólidos, realizadas neste ambiente de pesquisa, mostram ainda que, para formarmos indivíduos com uma visão crítica e transformadora, capazes de pensar por si mesmo e assim tomar decisões conscientes, faz-se necessário que as atividades de sensibilização sejam atividades em que as vertentes teoria e prática estejam atreladas, e que é importante, também, que as ações de Educação Ambiental voltadas para a reutilização de algum tipo de resíduo, mostrem o papel de cada individuo no ambiente, para que o desejo de um ambiente mais limpo e efetivamente conservado se torne uma realidade.

\section{Agradecimentos}

Ao grupo de senhora do Bairro Bela Vista, em Vitória de Santo Antão PE, pela presença e participação durante a pesquisa; à Universidade Federal de Pernambuco, e ao Programa UFPE na Praça por tornar possível a realização e conclusão do presente trabalho.

\section{Referências}

BIANCO, S. C. Avaliação Qualitativa. São Paulo: Editora Espaço, 1987.

BRASIL, Lei 6.938 de 31 de agosto de 1981. Dispõe sobre a Política Nacional do Meio Ambiente, seus fins e mecanismos de formulação e aplicação, e dá outras providências. Poder Legislativo, Senado, Brasília, DF, 1981.

CALDERONI, S. Os bilhões perdidos no lixo. SP: Humanistas, 1997. CARVALHO, I.C.M. Educação ambiental: a formação do sujeito ecológico. $4^{\circ}$ Ed. - São Paulo: Cortez, 2008.

EIGENHEER, E.M. História do lixo. Rio de Janeiro: ELS2 Comunicação. 144 p., 2009.

FELIX, R.A.Z. Coleta Seletiva em Ambiente Escolar. Revista Eletrônica do Mestrado em Educação Ambiental ISSN 1517-1256, v.18, janeiro a junho de 2007. 
GIL, A.C. Métodos e técnicas de pesquisa social. 5. ed. São Paulo: Atlas, 1999.

GIL, A.C. Como elaborar projetos de pesquisa. São Paulo: Atlas, 2008.

GOHM, M.G. Educação não-formal e cultura política: Impactos sobre 0 associativismo do terceiro setor. São Paulo, Cortez. 1999.

GUSMÃO, O.S. et al. Reciclagem artesanal na UEFS: estratégia educacional na valorização do meio ambiente. Anais.do CONGRESSO NACIONAL DE MEIO AMBIENTE NA BAHIA, 2., 2000. Salvador: UFBA, p, 56-58, 2000.

FERNANDES, R.S. (coord.), et al., Uso Da Percepção Ambiental Como Instrumento De Gestão Em Aplicações Ligadas Âs Áreas Educacional, Social E Ambiental. [s.I.]; [s.d.]. Salvador: UFBA, p 56-58, 2000.

JACOBI, P. Cidade e meio ambiente: percepções e práticas em São Paulo. São Paulo: Annablume, (2 ${ }^{\underline{a}}$ ed.: 2006), 206p. (ISBN 85-7419-102-7), 1999.

JACOBI, P. Meio Ambiente e Sustentabilidade: o Complexo Desafio da Sustentabilidade - Programa de Pós-Graduação em Ciência Ambiental da USP, 1994.

JACOBI, P. Educação Ambiental, Cidadania E Sustentabilidade. Cadernos de Pesquisa, n. 118, mp. a1rç8o9/-220050,3 março/ 2003.

LEMOS, J.C.; LIMA, S.C.; ALVIM, N.M.C. Segregação de resíduos de serviços de saúde para reduzir os riscos à saúde pública e ao meio ambiente. Bioscience Journal. Vol.15, n², p.64-72. Uberlândia: Universidade Federal de Uberlândia, 1999.

MEADOWS, D. et al. Os limites do crescimento. São Paulo: Perspectiva, 1972.

MILARÉ, E. Direito do Ambiente. 3.ed. São Paulo: Revista dos Tribunais, 2004.

MIZIARA, R. Por uma história do lixo. Interfacehs - Revista de Gestão Integrada em Saúde do Trabalho e Meio Ambiente - v.3, n.1, 2008.

MORIN, E. Os sete saberes necessários à educação do futuro. São Paulo : Cortez ; Brasília, DF: UNESCO, 2000.

MORIN, E. A cabeça bem-feita: repensar a reforma reformar o pensamento. Rio de Janeiro: Bertrand Brasil, 2000.

SÃO PAULO. Educação ambiental e desenvolvimento: documentos oficiais, Secretaria do Meio Ambiente, Coordenadoria de Educação Ambiental, São Paulo, Série Documentos, ISSN 0103-264X, 1994.

VELLOSO, M.P. Os catadores de materiais recicláveis e a gestão de resíduos. Apresentado no VIII Congresso Luso-Afro-Brasileiro de Ciências Sociais, Coimbra: 2004.

VIEIRA, E.; VALQUIND, L. Oficinas de Ensino: O quê? Por quê? Como? 4ํㅜㄴ ed. Porto Alegre. EDIPUCRS, 2002. 